\title{
Light transmittance of fiber posts following various surface treatments: A preliminary study
}

\author{
Isil Cekic-Nagas ${ }^{1}$, Gulfem Ergun ${ }^{1}$, Ferhan Egilmez ${ }^{1}$
}

Correspondence: Dr. Isil Cekic-Nagas

Email: isilcekic@gmail.com
'Department of Prosthodontics, Faculty of Dentistry, Gazi University, Ankara, Turkiye

\section{ABSTRACT}

Objective: The objective of this study was to compare the light transmittance of fiber posts following application of various surface treatments. Materials and Methods: Fiber post specimens (Snowpost red size \#14) were tested $(n=7)$. The fiber posts were divided into five groups according to the application of surface treatments: Group 1: No surface treatment; Group 2: Etched with hydrofluoric acid (HF) + silane application; Group 3: Airborne-particle abraded with $110 \mu \mathrm{m} \mathrm{Al}_{2} \mathrm{O}_{3}$; Group 4: Irradiated with erbium: Yttrium-aluminum-garnet laser; Group 5: Airborne-particle abraded with $110 \mu \mathrm{m} \mathrm{Al}_{2} \mathrm{O}_{3}+$ silane application. The light transmittance of the specimens was compared using a spectrophotometer. Statistical significance was determined using one-way analysis of variance (ANOVA) $(\alpha=0.05)$. Results: One-way ANOVA revealed that surface treatment had significant effects on light transmittance of posts $(P<0.001)$. While laser treatment had the highest percentage of light transmittance, treatment with silane following HF application had the lowest. Conclusion: Application of surface treatments might negatively affect the light transmission property of fiber posts.

Key words: Fiber post, laser, light transmittance, surface treatment

\section{INTRODUCTION}

The restoration of endodontically treated teeth with all-ceramic units in high demand esthetic zone, led to the introduction of esthetic posts such as glass fiber reinforced composite resin posts (FRC), and yttrium stabilized zirconia-based ceramic posts which are tooth-colored. ${ }^{[1,2]}$ FRC posts consist of fibers (carbon, quartz, silica, zirconia, or glass) in a resin matrix with a silane coupling agent binding the fibers and matrix together. ${ }^{[3]}$ In addition, the major advantage of the FRC posts is the elastic modulus, which is equal to that of dentin, as well as high durability which may lead to a better distribution of the occlusal loads along the root. ${ }^{[2,4]}$

The use of resin-based luting agents indicated for the retention of fiber post avoid friction between

\begin{tabular}{|l|l|}
\hline \multicolumn{2}{|c|}{ Access this article online } \\
\hline Quick Response Code: \\
\hline
\end{tabular}

root canal walls and passively retained posts. ${ }^{[5,6]}$ In addition, the retention of the post is one of the critical factors that could influence the quality of the restoration. Therefore, for adequate clinical function and for reliable bond formation at the root-postcore interfaces, the use of dual-cured or self-curing resin-based cements has been recommended. ${ }^{[7]}$ To convert monomer into polymer in resin-based material, resin cements should be polymerized properly. ${ }^{[8-10]}$ Moreover, the higher degree of monomer conversion is associated with improvements in the mechanical properties and of resin-based materials. ${ }^{[11]}$ Besides, the posts should transmit light to reach an adequate degree of cure at depth to permit curing of the cement throughout the apical region of the

This is an open access article distributed under the terms of the Creative Commons Attribution-NonCommercial-ShareAlike 3.0 License, which allows others to remix, tweak, and build upon the work non-commercially, as long as the author is credited and the new creations are licensed under the identical terms.

For reprints contact: reprints@medknow.com

How to cite this article: Cekic-Nagas I, Ergun G, Egilmez F. Light transmittance of fiber posts following various surface treatments: A preliminary study. Eur J Dent 2016;10:230-3.

DOI: $10.4103 / 1305-7456.178303$ 
tooth. ${ }^{[12]}$ Therefore, translucent fiber posts are used to overcome the problem of lack of curing in deep regions of root. ${ }^{[10]}$

To improve bonding of resin cements to posts, various surface pretreatment procedures including the use of mechanical or chemical agents for posts have been suggested. Previously reported surface treatments such as airborne-particle abrasion and acid etching with hydrofluoric acid (HF) are commonly used methods that result in roughened surface or manage chemical bonding between a resin cement and post. ${ }^{[3,4]}$

Recently, laser etching technology has become available as an alternative for improving roughness and bond strength of dental substrates and materials. ${ }^{[8,13]}$ The laser types employed in dentistry are argon laser, neodymium-doped yttrium aluminum garnet (Nd: YAG) laser, diode laser, erbium-doped YAG (Er: YAG), and erbium, chromium: Yttrium, scandium, gallium, garnet (Er, Cr: YSGG), and traditionally classified based on the active medium, for example, gas, liquid, solid state, or semiconductor diode. ${ }^{[14]}$ The newly introduced laser, Er, Cr: YSGG, is proposed for treatment of both soft and hard tissues with minimal thermal side-effects with a wavelength of $2.79 \mu \mathrm{m}$ and represents strong absorption in water $(\mu \mathrm{a}=7000 / \mathrm{cm}){ }^{[14,15]}$

Previously, few reports have evaluated the light transmitting ability of posts..$^{[7,16,17]}$ However, to date, no studies have examined the effect of surface treatment including laser treatment on light transmitting ability of fiber posts. Therefore, the tested null hypothesis was the surface treatment of fiber posts adversely affect light transmitting ability of fiber posts. Based on these considerations, the aim of this study was to investigate the effect of surface treatments on light transmittance of fiber posts.

\section{MATERIALS AND METHODS}

Prefabricated glass fiber posts (Snowpost; Carbotech, Ganges, France) ( $n=7 /$ per group) were prepared to a length of $10 \mathrm{~mm}$ and a coronal diameter of $1.5 \mathrm{~mm}$.

The surface treatments were confined to a $8 \mathrm{~mm}$ wide parallel band measured from the coronal end. In Group 1, no surface treatment was performed, and it served as control. In Group 2, posts were etched with 9.6\% HF for $60 \mathrm{~s}$ and rinsed with deionized water for $2 \mathrm{~min}$. Then silanization (Espe Sil) was performed for $60 \mathrm{~s}$. In Group 3, the posts were sandblasted with
$110 \mu \mathrm{m}$ diameter aluminum oxide particles (Rocatec Pre; 3M Espe) at a distance of $1 \mathrm{~cm}$ at 2.8 bar for 5 s. In Group 4, the posts were also sandblasted with $110 \mu \mathrm{m}$ diameter aluminum oxide particles for $5 \mathrm{~s}$ and silanated for $60 \mathrm{~s}$. In Group 5, the posts were irradiated with erbium, chromium: Yttrium, aluminum, garnet laser. The bonding surfaces of the post specimens were irradiated with an Er-Cr: YSGG laser system (Waterlase MD, Biolase Technology Inc., San Clemente, CA, USA) operating at a wavelength of $2780 \mathrm{~nm}$ and having pulse duration of $140-200 \mu \mathrm{s}$ with a repetition rate of $10 \mathrm{~Hz}$. The power output was set at $1.5 \mathrm{~W}$. In addition, the average exposure time was set at $10 \mathrm{~s}$, and the distance of application was $10 \mathrm{~mm}$. Moreover, air and water spray from the handpiece was adjusted to a level of $85 \%$ air and $85 \%$ water during the lasing of the specimens.

Schematic test set-up is given in Figure 1. Light transmission was measured using a transmission optical light microscope coupled with a spectrometer (Perkin-Elmer FT-IR System 2000 Model, CA, USA). The measurements were performed from the bottom end of each post. The referenced light source up were transmitted through the cut end and measured the intensity percentage of light (compared with the reference of $100 \%$ ) for each post. Values are given as the percentage of incident light measured at the opposite length of the post.

\section{Statistical analysis}

Statistical significance was determined by a one-way analysis of variance (ANOVA) followed by Tukey's post hoc test. Statistical analyses were performed using SPSS, version 20.0 (SPSS Inc., Chicago, IL, USA).

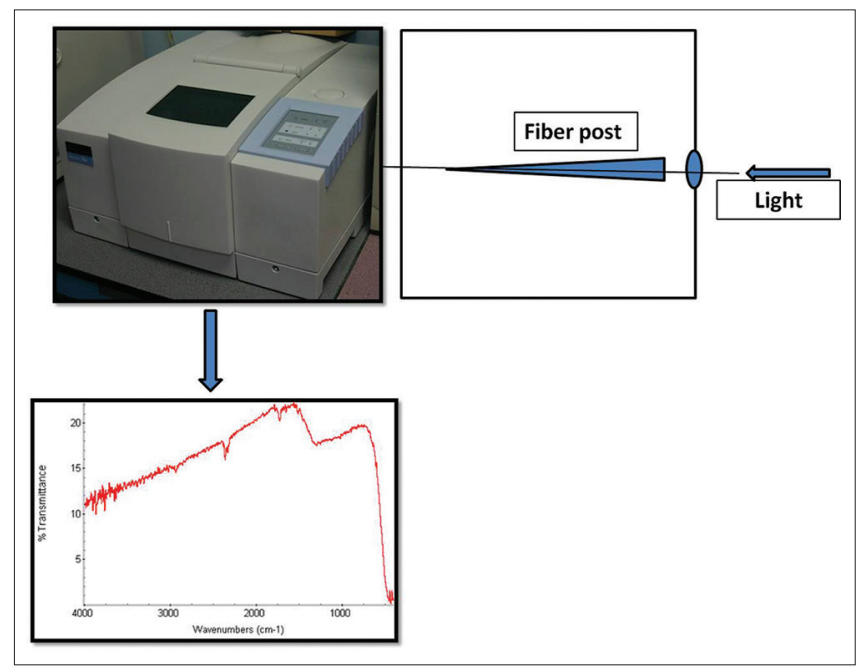

Figure 1: Schematic test set-up 


\section{RESULTS}

The mean light transmittance percentage values, standard deviations, and the differences within the groups are presented in Figure 2. One-way ANOVA revealed that the surface treatments had significant effects on bond strength values $(P<0.001)$. While the highest light transmittance value was achieved following laser treatment $(49.83 \pm 4.28)$, the lowest value was obtained with silane treatment following HF application (38.19 \pm 1.01$)$. The light transmittance values were ranked as follows: Control $>$ laser $>$ sandblasting $\geq$ silane application following sandblasting $\geq$ silane treatment following HF application [Figure 2].

\section{DISCUSSION}

The null hypothesis was accepted as statistical analysis revealed differences between light transmittance percentage values of the posts following different surface treatments. It is known that the most important aspect in cementation of a fiber post in the root canal is the limitation of the cure rate as a function of the depth. ${ }^{[10]}$ In addition, residual unreacted monomers formed as a result of incomplete polymerization of the resin cement and adhesive. Moreover, these materials might leak through the apical root filling and could result in inflammatory, cytotoxic, and mutagenic reactions of periodontal tissue. ${ }^{[16,17]}$ Therefore, to perform adequate light polymerization, the posts should transmit light to permit curing of the cement throughout the apical region of the tooth. ${ }^{[18]}$

A previous study by Radovic et al. investigated the light transmission through fiber posts and concluded that

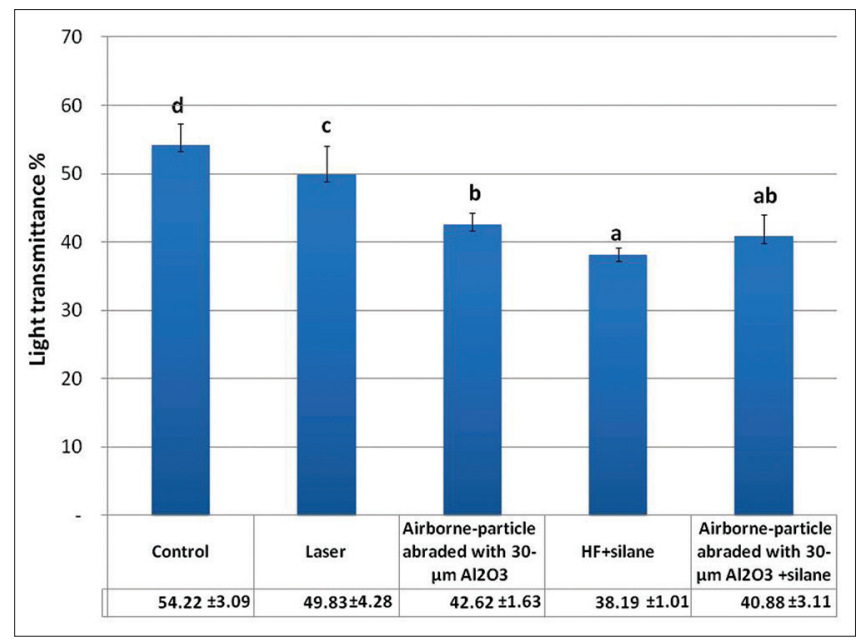

Figure 2: Light transmittance percentage values and standard deviations of the groups cementation of fiber post with no light transmitting ability using dual-cured resin cement resulted in lower percentage of continuity of resin cement-root dentin and resin cement-fiber post in comparison to cementation of light transmitting fiber post. ${ }^{[17]}$ They related this result with the presence of silica-zirconia fibers in the structure of fiber post used in that study. Similarly, the fiber posts used in this study was an esthetic post, composed of silica-zirconia fibers embedded in a resin matrix which might adversely influenced its light transmitting properties as the value of the control group was $54.22 \pm 3.09 \%$. In addition, a previous study by Goracci $e t$ al. evaluated light transmission behavior of translucent posts and found values lower than $40 \%$ of incident light. ${ }^{[16]}$ However, in this study, except the group treated with silane following HF application $(38.19 \pm 1.01)$, all the groups showed values higher than $40 \%$. This could be attributed to the differences between fiber contents and matrix structure of the posts.

In a previous study, the authors evaluated the effect of surface treatments on bond strength of resin core materials to three different types of fiber posts. ${ }^{[3]}$ They indicated that surface treatment with HF was found to be effective method for improving the bonding of resin core materials to fiber posts except one post group and related this result with modification of the fiber post surfaces with HF. In addition, an enhancement of the surface roughness and a greater exposure of the fibers in comparison to the untreated post might have occurred. In addition, a previous study by Samimi et al. compared pretreatment methods $(\mathrm{HF}+$ silane and $\mathrm{H}_{2} \mathrm{O}_{2}+$ silane) of a fiber post on the push-out bond strength to root and showed that dissolution of resin matrix and glass fibers created a rough surface. ${ }^{[19]}$ Besides, in a previous study by Hsu et al., ${ }^{[20]}$ it was stated that surface roughness might affect light scattering properties. Therefore, the lower light transmission values of the group treated with silane following HF application might be related with the surface roughness and thereby decrease in light transmission values. In addition, a previous study by Harada et al. indicated that the light scattering intensity increases as the substrate roughness increases. ${ }^{[21]}$

The Er, Cr: YSGG laser chosen in this study was introduced with two different wavelengths to avoid the increase in the temperature of the dental pulp and absorption problems of carbon dioxide laser and the Nd: YAG laser. ${ }^{[22]}$ The lasers are also used to prepare dental materials for bonding on or into tooth surfaces. ${ }^{[23]}$ The specimens treated with 
laser demonstrated a higher percentage of light transmittance than HF treated and sandblasted groups. This could be attributed to lower deterioration of fiber post surfaces with laser treatment. Furthermore, a previous study evaluated the surface roughness and bond strength of glass fiber posts to a resin cement after various surface treatment and found fiber ruptures in the sandblasted posts when compared with Er: YAG laser irradiated specimens. Moreover, in this study, lower power setting was used $(1.5 \mathrm{~W})$ in accordance with a previous study, ${ }^{[24]}$ and the surfaces were irradiated with constant water and air cooling. Besides, application parameters of lasers such as energy, output power, pulse duration, and distance could affect surface characteristics and thereby light transmission values of posts. In addition, Goracciet al. assimilated glass fiber to a multimode fiber optic. As they reported previously, the fiber acts like a core, the matrix like a cladding. In accordance with that study, the differences in the percentage of light transmission values among the posts could be possibly explained by the differences in refraction indices between the core and the cladding materials. ${ }^{[16]}$

Since the conversion of the present in vitro data to clinical outcomes constitutes great difficulty, clinical studies focusing on the effect of laser on dental materials' are needed. Therefore, further research is necessary to evaluate the optical properties of fiber posts in correlation with bond strength of posts to the resin cement in the root canal.

\section{CONCLUSION}

The surface treatments on fiber post might have negative effects on light transmitting properties.

\section{Financial support and sponsorship}

Nil.

\section{Conflicts of interest}

There are no conflicts of interest.

\section{REFERENCES}

1. Bitter K, Priehn K, Martus P, Kielbassa AM. In vitro evaluation of push-out bond strengths of various luting agents to tooth-colored posts. J Prosthet Dent 2006;95:302-10.

2. Egilmez F, Ergun G, Cekic-Nagas I, Vallittu PK, Lassila LV. Influence of cement thickness on the bond strength of tooth-colored posts to root dentin after thermal cycling. Acta Odontol Scand 2013;71:175-82.

3. Cekic-Nagas I, Sukuroglu E, Canay S. Does the surface treatment affect the bond strength of various fibre-post systems to resin-core materials? J Dent 2011;39:171-9.

4. Naves LZ, Santana FR, Castro CG, Valdivia AD, Da Mota AS, Estrela C, et al. Surface treatment of glass fiber and carbon fiber posts: SEM characterization. Microsc Res Tech 2011;74:1088-92.

5. Mannocci F, Innocenti M, Ferrari M. Stereomicroscopic and scanning electron microscopic study of roots obturated with vertically condensed gutta-percha, epoxy resin cement, and dentin bonding agent. J Endod 1998;24:397-400.

6. Goracci C, Grandini S, Bossù M, Bertelli E, Ferrari M. Laboratory assessment of the retentive potential of adhesive posts: A review. J Dent 2007;35:827-35.

7. Teixeira EC, Teixeira FB, Piasick JR, Thompson JY. An in vitro assessment of prefabricated fiber post systems. J Am Dent Assoc 2006;137:1006-12.

8. Vano M, Goracci C, Monticelli F, Tognini F, Gabriele M, Tay FR, et al. The adhesion between fibre posts and composite resin cores: The evaluation of microtensile bond strength following various surface chemical treatments to posts. Int Endod J 2006;39:31-9.

9. Faria e Silva AL, Casselli DS, Ambrosano GM, Martins LR. Effect of the adhesive application mode and fiber post translucency on the push-out bond strength to dentin. J Endod 2007;33:1078-81.

10. dos Santos GB, Alto RV, Filho HR, da Silva EM, Fellows CE. Light transmission on dental resin composites. Dent Mater 2008;24:571-6.

11. Cekic-Nagas I, Ergun G. Effect of different light curing methods on mechanical and physical properties of resin-cements polymerized through ceramic discs. J Appl Oral Sci 2011;19:403-12.

12. Shadman N, Atai M, Ghavam M, Kermanshah H, Ebrahimi SF. Parameters affecting degree of conversion of dual-cure resin cements in the root canal: FTIR analysis. J Can Dent Assoc 2012;78:c53.

13. Martínez-Insua A, Da Silva Dominguez L, Rivera FG, Santana-Penín UA. Differences in bonding to acid-etched or Er: YAG-laser-treated enamel and dentin surfaces. J Prosthet Dent 2000;84:280-8.

14. Subramaniam P, Pandey A. Effect of erbium, chromium: Yttrium, scandium, gallium, garnetlaser and casein phosphopeptide-amorphous calcium phosphate on surface micro-hardness of primary tooth enamel. Eur J Dent 2014;8:402-6.

15. Alavi S, Birang R, Hajizadeh F. Shear bond strength of orthodontic brackets after acid-etched and erbium-doped yttrium aluminum garnet laser-etched. Dent Res J (Isfahan) 2014;11:321-6.

16. Goracci C, Corciolani G, Vichi A, Ferrari M. Light-transmitting ability of marketed fiber posts. J Dent Res 2008;87:1122-6.

17. Radovic I, Corciolani G, Magni E, Krstanovic G, Pavlovic V, Vulicevic ZR, et al. Light transmission through fiber post: The effect on adhesion, elastic modulus and hardness of dual-cure resin cement. Dent Mater 2009;25:837-44.

18. Ferrari M, Breschi L, Grandini S. Fiber Posts and Endodontically Treated Teeth: A Compendium of Scientific and Clinical Perspectives of the Cement. $1^{\text {st }} \mathrm{ed}$. Singapore: Modern Dentistry Media; 2008.

19. Samimi P, Mortazavi V, Salamat F. Effects of heat treating silane and different etching techniques on glass fiber post push-out bond strength. Oper Dent 2014;39:E217-24.

20. Hsu FH, Wang NF, Tsai YZ, Chien MH, Houng MP. Improvement of short-circuit current density in p-o: Li/n-si heterojunction solar cells by wet chemical etching. J Nanomater 2014;2014:1-7.

21. Harada T, Murotani H, Matumoto S, Honda H. Influence of substrate surface roughness on light scattering of $\mathrm{TiO}_{2}$ optical thin films. Chin Opt Lett 2013;11:1-4.

22. Hoshing UA, Patil S, Medha A, Bandekar SD. Comparison of shear bond strength of composite resin to enamel surface with laser etching versus acid etching: An in vitro evaluation. J Conserv Dent 2014;17:320-4.

23. Akova T, Yoldas O, Toroglu MS, Uysal H. Porcelain surface treatment by laser for bracket-porcelain bonding. Am J Orthod Dentofacial Orthop 2005;128:630-7.

24. Sipahi C, Piskin B, Akin GE, Bektas OO, Akin H. Adhesion between glass fiber posts and resin cement: Evaluation of bond strength after various pre-treatments. Acta Odontol Scand 2014;72:509-15. 